\title{
Effects of bovine lactoferrin on the immature porcine intestine
}

\author{
Duc Ninh Nguyen ${ }^{1}$, Yanqi Li ${ }^{2,3}$, Per T. Sangild ${ }^{2}$, Stine B. Bering ${ }^{2}$ and Dereck E. W. Chatterton ${ }^{1 *}$ \\ ${ }^{1}$ Department of Food Science, Faculty of Science, University of Copenhagen, DK1958 Frederiksberg C, Denmark \\ ${ }^{2}$ Department of Nutrition, Exercise and Sports, Faculty of Science, University of Copenhagen, \\ DK-1870 Frederiksberg C, Denmark \\ ${ }^{3}$ Arla Foods Ingredients Group P/S, Viby J, Denmark \\ (Submitted 5 March 2013 - Final revision received 25 June 2013 - Accepted 3 July 2013 - First published online 6 August 2013)
}

\section{Abstract}

Bioactive milk proteins may be important in protecting preterm infants from developing inflammation and necrotising enterocolitis (NEC). A preterm pig model was used to investigate the protective effects of enteral bovine lactoferrin (bLF) against NEC development and inflammation. Caesarean-delivered preterm pigs were fed parenteral and minimal enteral nutrition for the first $2 \mathrm{~d}$ followed by $2 \mathrm{~d}$ of total enteral nutrition before euthanasia. Pigs were stratified into two groups and fed with either a control formula (CON, $n$ 15) or a $10 \mathrm{~g} / \mathrm{l}$ of bLF-enriched formula (LF, $n$ 13). NEC incidence, gut functions and inflammatory cytokines were analysed. NEC incidence and nutrient absorption were similar between the two groups. In pigs that developed NEC, disease outcome was more severe in the colon accompanied by increased intestinal permeability in LF pigs. In contrary, the LF pigs had a lowered IL-1 $\beta$ level in the proximal small intestine. Dosedependent effects of bLF on cell proliferation, intracellular signalling and cytokine secretion were tested in porcine intestinal epithelial cells (PsIc1) in vitro. Low doses $(0 \cdot 1-1 \mathrm{~g} / 1)$ increased cell proliferation via extracellular signal-regulated kinase (ERK), limited IL- 8 secretion and prevented NF- $\mathrm{KB}$ and hypoxia-inducible factor- $1 \alpha$ (HIF- $1 \alpha)$ activation, suggesting anti-inflammatory effects. In contrast, at a higher dose $(10 \mathrm{~g} / \mathrm{l})$, bLF exerted adverse effects by reducing cell proliferation, stimulating IL- 8 release, inhibiting ERK activation and up-regulating NF- $\mathrm{KB}$ and HIF- $1 \alpha$ activation. Overall, at a dose of $10 \mathrm{~g} / \mathrm{l}$, bLF exacerbated disease severity in pigs that developed NEC, while the in vitro studies indicated the positive effects of bLF at low doses $(0 \cdot 1-1 \mathrm{~g} / \mathrm{l})$. Supplementation of infant formulas with bLF should therefore be optimised carefully.

\section{Key words: Inflammatory cytokines: Lactoferrin: Necrotising enterocolitis: NF-кB}

Necrotising enterocolitis (NEC) is one of the most common and severe intestinal diseases in human preterm infants with an incidence of $7 \%$ in very-low-birth-weight infants $(<1500 \mathrm{~g})$ and a mortality rate of $20-30 \%{ }^{(1)}$. The causes of NEC are still poorly understood, but some major predisposing factors are prematurity, aggressive enteral feeding and improper microbial colonisation in the intestine ${ }^{(1)}$. Human milk is considered as the optimal diet for both term and preterm infants $^{(2)}$, but a large proportion (e.g. 20-40\%) of preterm and term infants are not breast-fed ${ }^{(3)}$. In such cases, breast milk is replaced by human donor milk, bovine milk-derived human milk fortifiers or infant formulas, but these may increase the risk of NEC development. Several clinical studies have indicated that exclusively feeding human milk to preterm infants decreases NEC incidence and lowers mortality significantly ${ }^{(4-6)}$, compared with adding a bovine milk-based human milk fortifier $(1 \cdot 7-3 \cdot 2 v \cdot 15 \cdot 3 \%)$ or feeding an infant formula $^{(7,8)}$. The reason for this may be that specific bioactive components in human milk can contribute to the protection against NEC. Studies focusing on the bioactivity of these individual components can provide knowledge for the development of a new generation of improved formulas containing proteins supplemented at doses similar to those in human milk.

Lactoferrin is an important $80 \mathrm{kDa}$ Fe-binding protein present in mammalian milk and in several secreted fluids such as saliva and mucosal secretions ${ }^{(9-11)}$. It is a major human milk protein having a concentration of up to $7 \mathrm{~g} / \mathrm{l}$ in the human colostrum and $2 \mathrm{~g} / \mathrm{l}$ in mature $\operatorname{milk}^{(9)}$. In contrast, it is present in bovine milk as a minor protein $(1.5$ and $0.2 \mathrm{~g} / 1$ in the colostrum and mature milk, respectively) ${ }^{(9)}$. The structure of lactoferrin comprises an N-terminal and a C-terminal domain linked by a hinge region, which causes protein flexibility $^{(11,12)}$. Human lactoferrin and bovine lactoferrin (bLF) are

Abbreviations: bLF, bovine lactoferrin; CON, control formula; HIF-1 $\alpha$, hypoxia-inducible factor-1 $\alpha$; I $\mathrm{KB}$, inhibitor $\kappa \mathrm{B}$; LF, bovine lactoferrin-enriched formula; LPS, lipopolysaccharide; NEC, necrotising enterocolitis; PARP-1, poly(ADP-ribose) polymerase 1; PsIc1, porcine intestinal epithelial cells; TEN, total enteral nutrition.

*Corresponding author: D. E. W. Chatterton, fax +4535333190, email dcha@life.ku.dk 
partially stable after gastrointestinal digestion in infants, and thereby bind to lactoferrin receptors in the gut with high affinity and exert bioactivity ${ }^{(13,14)}$. In humans, lactoferrin receptors are located on the apical side of the intestinal epithelium and expressed in large amounts during the fetal and neonatal periods ${ }^{(15)}$. The bioactive effects associated with lactoferrin in vitro include mediation of immune responses and antimicrobial activities against bacteria, viruses and parasites ${ }^{(16)}$. Intact lactoferrin itself or its fragments released during digestion, such as its C-lobe and lactoferricin, bind to pathogenic bacteria, thereby preventing epithelial attachment and infection ${ }^{(16)}$. Furthermore, lactoferrin stimulates in vitro cell proliferation ${ }^{(17,18)}$, which may benefit the immature intestine in preterm infants. Several studies have indicated that bLF attenuates lipopolysaccharide (LPS)-induced inflammatory cytokines such as IL-8, IL-6, IL-1 $\beta$ and TNF- $\alpha$ in monocytic cells ${ }^{(19)}$ and IL-8 in Caco-2 cells ${ }^{(20)}$ via NF- $\mathrm{B}$ modulation, thus offering a potential for the prophylaxis of inflammation. Another important characteristic of this protein is its high Fe-binding affinity (approximately $\left.K=10^{22} \mathrm{M}\right)^{(21)}$, which is associated with a recent finding of lactoferrin as a mimetic of hypoxia due to this Fe-binding ability. This results in the stabilisation of hypoxia-inducible factor- $1 \alpha$ (HIF-1 $\alpha)$, which is also linked with NF- $\mathrm{B}$ during inflammation $^{(22,23)}$.

Importantly, bLF and human lactoferrin share $77 \%$ amino acid homology and have similar structures ${ }^{(24)}$. As a consequence, their biological activities are similar; for instance, they have comparable in vitro anti-microbial activities ${ }^{(16)}$. Therefore, bLF could be a key component in protecting newborn infants from diseases in early life. For instance, oral administration of bLF at a dose of $240-400 \mathrm{mg} / \mathrm{kg}$ per $\mathrm{d}$ demonstrated positive effects in vivo against intestinal diseases such as reducing the incidence of dextran sulphate sodiuminduced colitis in rats and attenuating inflammatory cytokines (IL-6, TNF- $\alpha$ and IL-1 $\beta)^{(25)}$. In addition, administration of bLF at a dose of $100 \mathrm{mg} / \mathrm{d}$ to preterm neonates for the first $30 \mathrm{~d}$ of life conferred protection against sepsis, but not $\mathrm{NEC}^{(24)}$. Currently, bLF is used as a supplement in infant formulas, although the range of optimal doses is not known.

We hypothesised that the bioactive effects associated with bLF in milk or formulas may potentially prevent excessive inflammatory responses and the risk of NEC development in immature preterm neonates. We used an established preterm pig model of $\mathrm{NEC}^{(26)}$ to study the effects of bLF supplementation of infant formulas $(10 \mathrm{~g} / \mathrm{l}$ of bLF, equivalent to $1.2 \mathrm{~g} / \mathrm{kg}$ per $\mathrm{d}$ during the period of administration of total enteral nutrition (TEN), which is close to that present in the human colostrum) against NEC development. The bLF dose used was greater than what has been tested in previous in vivo studies $^{(24,25)}$, and this was hypothesised to exert stronger effects against NEC. Moreover, a wide range of bLF doses $(0 \cdot 1-10 \mathrm{~g} / \mathrm{l})$ were investigated using porcine intestinal epithelial cells (PsIc1) in vitro to determine the effects of bLF on cell proliferation, pro-inflammatory cytokine release as well as the mediation of ERK, NF- $\mathrm{BB}$ and HIF- $1 \alpha$ intracellular signalling pathways. These will elucidate a potentially appropriate range of bLF doses that can be selected for further animal and clinical studies in the future.

\section{Materials and methods}

\section{Animal experiments}

A total of twenty-eight preterm pigs from four sows were delivered by caesarean section (Large White $\times$ Danish Landrace $\times$ Duroc, Askelygaard Farm, Roskilde, Denmark) at $92 \%$ of gestational age ( $105 \mathrm{~d}$, term 116 (SEM 2) d). After delivery, pigs were immediately transferred to individual incubators maintained at $37^{\circ} \mathrm{C}, 80-100 \%$ humidity and a suitable oxygen administration before placing vascular catheters (4F, Portex) in the umbilical artery and orogastric feeding tubes (6F, Portex; Smiths Medical). Pigs were then provided with maternal serum of $4 \mathrm{ml} / \mathrm{kg}$ after catheterisation, and subsequently $5 \mathrm{ml} / \mathrm{kg}$ after $12 \mathrm{~h}$ and $7 \mathrm{ml} / \mathrm{kg}$ after $20 \mathrm{~h}$ to provide passive immunological protection. Pigs were stratified into two groups according to sex and weight with two types of enteral nutrition: control formula (CON, $n$ 15) and $10 \mathrm{~g} / \mathrm{l}$ of bLF-enriched formula (LF, $n$ 13). The two formulas were made by mixing various commercial ingredients to meet the optimal macronutrient and energy requirements for preterm pigs ${ }^{(26,27)}$ : Lacprodan DI-9224 (Arla Foods Ingredients); Ross Polycose (Abbott Nutrition); SHS Seravit, Liquigen Medium-chain TAG and Calogen Long-chain TAG (Nutricia); with or without bLF (Morinaga Milk Industry). The lactoferrin used was bLF with $15 \%$ Fe saturation and a low endotoxin content (1.6 endotoxin units/mg protein) detected by the Limulus Amebocyte Lysate Chromogenic Endotoxin Quantitation Kit (Fisher Scientific). The two formulas had similar composition except for the presence (LF) or absence (CON) of bLF, and they were adjusted to an equal intake of energy and macronutrients (Table 1). During the first $2 \mathrm{~d}$, pigs were administered parenteral nutrition through their umbilical catheters at rates of 4 and $6 \mathrm{ml} / \mathrm{kg}$ per $\mathrm{h}$ for days 1 and 2, respectively, supplemented with either the CON or LF formula as minimal enteral nutrition with doses of $3 \mathrm{ml} / \mathrm{kg}$ per $3 \mathrm{~h}$ at day 1 and $5 \mathrm{ml} / \mathrm{kg}$ per $3 \mathrm{~h}$ at day 2. Parenteral nutrition was based on Kabiven (Fresenius Kabi) and adjusted nutrient composition to meet the requirements of pigs with an energy of $3210 \mathrm{~kJ} / \mathrm{l}$ and a macronutrient energy composition of $36 \%$ fat, $24 \%$ protein and $40 \%$ carbohydrates. From day 3, parenteral nutrition was stopped, and the pigs were fed either the CON or LF formula as TEN administered at a dose of $15 \mathrm{ml} / \mathrm{kg}$ per $3 \mathrm{~h}$ for another $2 \mathrm{~d}$ until euthanasia and tissue collection on day 5 . The animal protocol was approved by the Danish National Committee on

Table 1. Macronutrient composition of the formulas used for enteral feeding in the control group (CON) and the lactoferrin-enriched formula group (LF)*

\begin{tabular}{lcc}
\hline & CON & LF \\
\hline Energy $(\mathrm{kJ} / \mathrm{l})$ & 4508 & 4508 \\
Total protein $(\mathrm{g} / \mathrm{l})$ & 79 & 79 \\
Protein $(\mathrm{g} / \mathrm{l})$ & 79 & 69 \\
bLF $(\mathrm{g} / \mathrm{l})$ & 0 & 10 \\
Carbohydrates $(\mathrm{g} / \mathrm{l})$ & 62.5 & 62.5 \\
Maltodextrin $(\mathrm{g} / \mathrm{l})$ & 47.5 & 47.5 \\
Lactose $(\mathrm{g} / \mathrm{l})$ & 15 & 15 \\
Fat $(\mathrm{g} / \mathrm{l})$ & 57 & 57 \\
\hline
\end{tabular}

bLF, bovine lactoferrin.

* These were calculated based on macronutrient analysis from suppliers. 
Animal Experimentation, and it has been described in detail previously ${ }^{(26,27)}$.

\section{Clinical evaluation and sample collection}

Every $3 \mathrm{~h}$ from birth to euthanasia, pigs were evaluated for NEC symptoms including bloody diarrhoea, abdominal distension, lethargy and cyanosis. Pigs with severe symptoms were euthanised immediately for tissue collection. Following euthanasia, the stomach, three regions of the small intestine (proximal, middle and distal) and the colon were macroscopically evaluated for NEC severity according to our standard scoring system: $1=$ no or minimal abnormality; 2 = mild focal gastroenterocolitis; $3=$ moderate locally extensive gastroenterocolitis; $4=$ severe focal gastroenterocolitis; $5=$ severe locally extensive haemorrhage and NEC; $6=$ severe extensive haemorrhage and NEC. Scores above 2 in any of the five gastrointestinal regions were considered as positive for NEC. After euthanasia, individual organs including the heart, lungs, liver, kidneys, spleen, stomach, small intestine and colon were weighed. The length of the small intestine was measured at a relaxed stage. From the middle of each intestinal region, five pieces of whole-wall intestinal tissue samples were taken and immediately snap-frozen in liquid $\mathrm{N}_{2}$ and stored at $-80^{\circ} \mathrm{C}$ for further analyses of enzymatic activities and cytokines. Another two samples of intestinal tissue from each region were stored in paraformaldehyde solution for histology. In addition, $10 \mathrm{~cm}$ segments of each intestinal region were sampled and slit longitudinally for the measurement of circumference and mucosal proportion. The mucosa was gently scraped to determine the proportion both wet weight and dry weight as described previously ${ }^{(26,27)}$.

\section{In vivo sugar absorption and intestinal permeability tests}

In vivo sugar absorption and intestinal permeability tests were conducted as described previously ${ }^{(28)}$ with modifications. Plasma levels of galactose in response to oral boluses of galactose and lactose solutions on days 3 and 4 , respectively, were analysed to measure the digestive and absorptive function of the gut. Blood samples were collected before and $20 \mathrm{~min}$ after an oral bolus $(15 \mathrm{ml} / \mathrm{kg})$ of $5 \%$ galactose for the galactose test on day 3 before conversion to TEN, and before and 20 and $40 \mathrm{~min}$ after an oral bolus $(15 \mathrm{ml} / \mathrm{kg})$ of $10 \%$ lactose for the lactose test $30 \mathrm{~h}$ after conversion to TEN. For the assessment of intestinal permeability, $3 \mathrm{~h}$ before euthanasia, an oral bolus $(15 \mathrm{ml} / \mathrm{kg}$ ) of $5 \%$ lactulose and 5\% mannitol solutions was given to pigs and post-mortem urine samples were collected at euthanasia. Permeability was quantified by the ratio of lactulose:mannitol concentrations in the urine as reported elsewhere ${ }^{(29)}$.

\section{Intestinal morphology, functions and tissue cytokine analyses}

Formaldehyde-fixed tissues from the proximal and distal small intestine and the colon were embedded in paraffin, transversely sectioned $(5 \mu \mathrm{m})$ and stained with haematoxylin and eosin for measurements of villus height and crypt depth ${ }^{(26)}$. Gut morphology including villus height and crypt depth was quantified from scanned photos using ImageJ software (National Institute of Health). For each pig, three representative cross-sections in each region were sampled and ten representative measurements of villus height and crypt depth were made. Intestinal brush-border enzymes, including sucrase, lactase, maltase, aminopeptidase A, aminopeptidase $\mathrm{N}$ and dipeptidyl-peptidase IV, were analysed according to previous protocols ${ }^{(26)}$ and are expressed as $\mathrm{U} / \mathrm{g}$ wet tissue. The cytokine levels of IL- 8 and IL- $1 \beta$ in the proximal and distal small intestine and the colon were quantified using ELISA following tissue homogenisation as described previously ${ }^{(30)}$. The levels of cytokines are expressed as $\mathrm{pg} / \mathrm{mg}$ wet tissue.

\section{Cell culture, cell proliferation and cytokine analysis}

PsIc1 intestinal epithelial cells from 6-month-old weaning pigs (Bionutritech) were cultured in advanced Dulbecco's modified Eagle's medium with supplementation of $2 \%$ heat-inactivated fetal bovine serum, $40 \mathrm{U}$ penicillin $/ \mathrm{ml}, 40 \mu \mathrm{g}$ streptomycin $/ \mathrm{ml}$ and $2 \mathrm{~mm}$-glutamine (Life Technologies) at $37^{\circ} \mathrm{C}$ and $5 \% \mathrm{CO}_{2}$. Cells were used at passage $5-25$. bLF was prepared by dissolving in serum-free DMEM medium and sterile filtered $(0 \cdot 2 \mu \mathrm{m})$ (Millipore).

For the cell proliferation assay, cells were seeded in ninetysix-well plates $\left(5 \times 10^{3}\right.$ cells/well) and allowed to adhere for $24 \mathrm{~h}$ before treatments with bLF $(0-20 \mathrm{~g} / \mathrm{l})$ for another $48 \mathrm{~h}$. For assessment of the effects of ERK, cells were pre-incubated with the mitogen-activated/extracellular signal-regulated kinase (MEK) 1/2 inhibitor PD98059 (70 $\mu \mathrm{M}$; Sigma-Aldrich) for $1 \mathrm{~h}$ before the treatments with bLF $(0-10 \mathrm{~g} / \mathrm{l})$ for $48 \mathrm{~h}$. Cell proliferation was quantified by the Celltiter 96 Aqueous One Solution Cell Proliferation Assay (Promega), according to the manufacturer's instructions.

For cytokine analysis, cells were cultured until reaching $90 \%$ confluency in twenty-four-well plates and then serum-starved for $24 \mathrm{~h}$. The cells were then incubated with bLF $(0-10 \mathrm{~g} / \mathrm{l})$ and/or LPS (0.1 $\mu \mathrm{g} / \mathrm{ml})$ (from Escherichia coli O26:B6; SigmaAldrich) for $24 \mathrm{~h}$. Thereafter, supernatants were collected for the analysis of IL- 8 and IL- 6 by ELISA, following the manufacturer's instructions (R\&D Systems). Cytokine concentrations were normalised to the total intracellular protein content (ng/mg protein). After the treatments and supernatant collection, cell lysates were taken and analysed using the BCA Protein Assay Kit (Fisher Scientific) for the total protein content.

\section{Intracellular signalling by Western blot}

Western immunoblotting was conducted as indicated previously ${ }^{(10)}$ with minor modifications. Cells at $90 \%$ confluency were serum-starved for $24 \mathrm{~h}$ before stimulation with bLF at a dose of $0 \cdot 1,1$ or $10 \mathrm{~g} / \mathrm{l}$ for different time periods $(5-90 \mathrm{~min})$ Following the treatments, cells were lysed in radio-immunoprecipitation assay lysate buffer containing $1 \times$ protease and phosphatase inhibitors (Fisher Scientific). Proteins in lysates $(10 \mu \mathrm{g})$ were separated by SDS-PAGE using $12.5 \%$ Tris-Glycine gels in non-reducing conditions before electro-transfer onto polyvinylidene difluoride membranes (Life Technologies) ${ }^{(10)}$. Membranes were then probed with 
anti-IкB- $\alpha$, anti-phospho-ERK, anti-HIF-1 $\alpha$ and anti-poly (ADP-ribose) polymerase 1 (PARP-1) antibodies (Santa Cruz) to detect the levels of intracellular inhibitor $\kappa$ B- $\alpha$ (IкB- $\alpha$ ), phosphorylated ERK 1/2, HIF-1 $\alpha$ and PARP-1 cleavage following the bLF treatment. In order to confirm the equal protein loading in each lane, membranes were stripped and re-probed to detect the total ERK or $\beta$-actin as the loading control. For the detection of NF-кB/p65, cells were treated with bLF as described above. Following the treatment, nuclear proteins were extracted using Nuclear and Cytoplasmic Extraction Reagents (Fisher Scientific), according to the manufacturer's instructions, before performing Western blot using rabbit anti-NF-кB/p65 antibody. Membranes were then stripped and re-probed to detect lamin B1 as the loading control. All primary antibodies were from Santa Cruz.

\section{Statistical analysis}

All data are reported as means with their standard errors. Differences in NEC incidence between the two groups were tested using a $\chi^{2}$ test (JMP 9; SAS Institute). Continuous data in the animal study were analysed by a linear mixed model using diet and region (when applicable) as fixed factors and sow and pig as random factors. All cell studies were performed in triplicate or quadruplicate. Comparisons between groups were performed using one-way ANOVA and Tukey's test in GraphPad Prism 5.0 (GraphPad Software, Inc.). Significance was considered at $P<0.05 . P$ values in the range of 0.05-0.1 were considered as non-significant trends.

\section{Results \\ Clinical assessments}

The incidence of NEC was $60 \%$ ( $n$ 9/15 pigs) in the CON group compared with $62 \%$ ( $n$ 8/13 pigs) in the LF group, with no difference in either NEC incidence or NEC severity (Fig. 1(a)). Within the subgroup of pigs that developed NEC, the degree of NEC severity in the colon was greater in the LF pigs than in the CON pigs (Fig. 1(b)). Average NEC severity scores for both the whole gastrointestinal tract and the small intestine of NEC pigs tended to be greater in the LF pigs than in the CON pigs $(P=0.07$ and 0.08 , respectively). The two groups did not differ in body weight at birth $(965.2$ (SEM 8.9) g), body-weight gain $(-3.4(\operatorname{sem} 2 \cdot 0) \mathrm{g} / \mathrm{d})$ and the relative weights $(\mathrm{g} / \mathrm{kg}$ body weight, pooled values) of lungs (24.3 (SEM 0.4)), liver (30.1 (SEM 1.1)), kidneys (10.6 (SEM 0.3)), stomach (9.2 (SEM 0.7)) and large intestine (16.2 (sem $0 \cdot 7)$ ) (Table 2 ). Only the relative heart weight was greater in the LF pigs.

\section{Mucosal structure, digestive functions and cytokine levels}

The dry mucosal proportion (Table 2), villus height and crypt depth (data not shown) were similar in the CON and LF pigs. When considering healthy pigs, the crypt depth of the proximal regions was greater in the LF pigs (88.6 (sEM 6.4) $\mu \mathrm{m}$ ) than in the CON pigs (80.9 (SEM 3.6) $\mu \mathrm{m}, P<0.05$ ) (Fig. 2). All the analysed activities of the brush-border membrane enzymes across the three small-intestinal regions did not
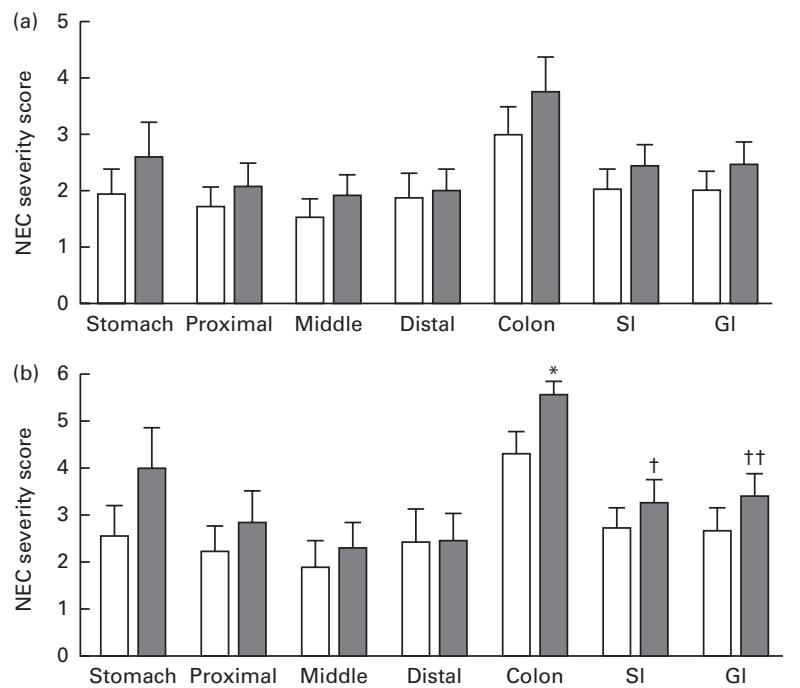

Fig. 1. Necrotising enterocolitis (NEC) severity in (a) all pigs and (b) NEC pigs in the small intestine (SI), total gastrointestinal tract (GI) and five gastrointestinal regions (stomach, proximal, middle and distal small intestine, and colon) based on the evaluation of macroscopic tissues. $\square$, Control pigs; $\square$, lactoferrin-enriched formula pigs. Values are means, with their standard errors represented by vertical bars. * Mean value was significantly different that of the control group $(P<0.05)$. Mean value tended to be greater than that of the control group: $\uparrow P=0.08, \dagger+P=0.07$.

differ between the two groups (Supplementary Fig. S1, available online). Sugar absorption measured by a galactose and a lactose test did not differ either. In NEC pigs only, intestinal permeability was greater in the LF pigs than in the CON pigs $(P<0.05$; Fig. 3). In contrast, higher levels of IL-1 $\beta$ were observed in the proximal small intestine of the CON pigs than that of the LF pigs $(P<0.05$; Fig. 4(a)). In addition, pooled IL-1 $\beta$ contents of the two groups were greater in the colon than in the distal small intestine $(P<0.05$; Fig. 4(a)). Conversely, there were no differences in the levels of IL- 8 between the two groups in both the proximal and distal small intestine as well as in the colon (Fig. 4(b)).

\section{Cell proliferation}

bLF exerted dose-dependent effects on cell proliferation in vitro (Fig. 5). At low doses (0.01 and $0 \cdot 1 \mathrm{~g} / \mathrm{l})$, bLF stimulated cell proliferation, while at excessive doses (10-20g/l), it decreased cell proliferation, when compared with the control (no treatment, $P<0 \cdot 01$ ) (Fig. 5(a)). The addition of the MEK $1 / 2$ inhibitor PD98059 before the treatments, which also inhibits the phosphorylation of ERK $1 / 2$, prevented the proliferative effects induced by bLF at the $0 \cdot 1 \mathrm{~g} / 1$ dose $(P<0.05$; Fig. 5(b)).

\section{Cytokine secretion modulated by bovine lactoferrin and lipopolysaccharide}

PsIc1 cells did not respond to LPS for the secretion of IL-8 (Fig. 6(a)), whereas at doses of $1-10 \mathrm{~g} / 1$, bLF stimulation induced IL-8 release. In addition, co-stimulation of bLF and LPS did not differ from the bLF treatments alone. IL- 6 release was increased by LPS alone or by bLF at low concentrations 
Table 2. Necrotising enterocolitis (NEC) incidence and relative organ dimensions in preterm pigs fed with the control formula (CON) and the lactoferrin-enriched formula (LF)

(Mean values with their standard errors)

\begin{tabular}{|c|c|c|c|c|c|}
\hline \multirow[b]{2}{*}{ Treatments } & \multicolumn{2}{|c|}{$\operatorname{CON}(n 15)$} & \multicolumn{2}{|c|}{$\operatorname{LF}(n 13)$} & \multirow[b]{2}{*}{$P^{*}$} \\
\hline & Mean & SEM & Mean & SEM & \\
\hline NEC incidence & & \multirow{2}{*}{\multicolumn{2}{|c|}{8}} & NS \\
\hline$n$ & \multirow{2}{*}{\multicolumn{2}{|c|}{$\begin{array}{c}9 \\
60\end{array}$}} & & & \\
\hline$\%$ & & & \multicolumn{2}{|c|}{62} & \\
\hline Body weight at birth (g) & $956 \cdot 3$ & 57.5 & 974.2 & $61 \cdot 7$ & NS \\
\hline Body-weight gain (g/d) & -1.4 & $5 \cdot 8$ & -5.4 & $7 \cdot 7$ & NS \\
\hline \multicolumn{6}{|l|}{ Organ weight $(\mathrm{g} / \mathrm{kg})$} \\
\hline Heart & $8 \cdot 1$ & 0.2 & $9 \cdot 1$ & 0.4 & $<0.05$ \\
\hline Lungs & $24 \cdot 8$ & 1.6 & 23.9 & 1.3 & NS \\
\hline Liver & $29 \cdot 1$ & $1 \cdot 3$ & $31 \cdot 2$ & $2 \cdot 0$ & NS \\
\hline Kidneys & $10 \cdot 3$ & 0.4 & $10 \cdot 8$ & 0.6 & NS \\
\hline Spleen & 1.7 & 0.1 & $2 \cdot 7$ & 0.8 & NS \\
\hline Stomach & 8.5 & 0.7 & $9 \cdot 9$ & 0.8 & NS \\
\hline Large intestine & $16 \cdot 9$ & 0.8 & $15 \cdot 5$ & $2 \cdot 2$ & NS \\
\hline Small intestine & $35 \cdot 2$ & $1 \cdot 8$ & $30 \cdot 5$ & 2.9 & $0 \cdot 10$ \\
\hline Small-intestinal length $(\mathrm{cm} / \mathrm{kg})$ & 354.9 & $16 \cdot 2$ & 333.0 & $20 \cdot 6$ & NS \\
\hline Mucosal proportion (\%) & 67.6 & $1 \cdot 6$ & $64 \cdot 1$ & $3 \cdot 1$ & NS \\
\hline Circumference across the small intestine $(\mathrm{mm})$ & $12 \cdot 0$ & 0.5 & $12 \cdot 6$ & 0.7 & NS \\
\hline
\end{tabular}

${ }^{*}$ Mean value was significantly different from that of the control group $(P<0.05)$.

(0.01-0.1 g/l; $P<0 \cdot 05)$. No differences in IL-6 secretion between LPS and LPS + bLF (0.01-1 g/1)-treated cells were observed (Fig. 6(b)). In contrast, at a dose of $10 \mathrm{~g} / \mathrm{l}$, bLF attenuated LPSinduced IL-6 release $(P<0 \cdot 05)$.

\section{Intracellular signalling regulated by bovine lactoferrin}

bLF treatments affected the activation of the ERK pathway in a dose-dependent manner. bLF treatments at doses of $0 \cdot 1-1 \mathrm{~g} / 1$ increased ERK activation observed by the phosphorylation of ERK $1 / 2(15 \mathrm{~min}$ for bLF at $0 \cdot 1 \mathrm{~g} / \mathrm{l}$ and $30 \mathrm{~min}$ for bLF at $1 \mathrm{~g} / 1$ compared with the control before gradually decreasing to the control levels after 60-90 min, $P<0.05$; Fig. 7(a), (b) and (d)). However, no changes in phosphorylated ERK $1 / 2$ occurred after the treatment with bLF at the dose of $10 \mathrm{~g} / 1$ (Fig. 7(c) and (d)). At higher doses (10g/l), bLF did not activate ERK and did not stimulate cell proliferation compared with the control. bLF stimulation at doses of 1 and $10 \mathrm{~g} / \mathrm{l}$, but not at $0 \cdot 1 \mathrm{~g} / 1$, caused the cleavage of PARP-1 $(P<0 \cdot 05)$ to form a $50 \mathrm{kDa}$ fragment (a marker of necrosis ${ }^{(31,32)}$; Fig. $7(\mathrm{e})$ and (f)). No fragment of $89 \mathrm{kDa}$ (a marker of apoptosis ${ }^{(31,32)}$ ) from PARP-1 was formed following bLF stimulation at all the doses tested.

We also studied the role of bLF in the regulation of NF-кB signalling. I $\kappa \mathrm{B}-\alpha$ is a protein bound to NF- $\kappa \mathrm{B}$, which prevents the translocation of NF- $\mathrm{B}$ from the cytoplasm into the nucleus ${ }^{(33,34)}$. Once I $\mathrm{I} B-\alpha$ is degraded, NF- $\kappa \mathrm{B}$ is released and subsequently translocated into the nucleus to act as a transcription factor to induce cytokine expression. Fig. 8 illustrates a dose-dependent effect of bLF on NF- $\kappa \mathrm{B}$ activation. IкB- $\alpha$ was stable at the bLF dose of $0 \cdot 1 \mathrm{~g} / 1$, slightly decreased after 60-90 min at the bLF dose of $1 \mathrm{~g} / \mathrm{l}$ and was degraded within $30 \mathrm{~min}$ after the bLF treatment at the dose of $10 \mathrm{~g} / \mathrm{l}$ (Fig. 8 (a)-(c) and (e)). These results suggest that only at bLF doses of 1 and $10 \mathrm{~g} / \mathrm{l}$, IкB- $\alpha$ degradation will occur and may cause NF- $\kappa \mathrm{B}$ translocation, and that the bLF dose of $10 \mathrm{~g} / \mathrm{l}$ may activate NF-кB more rapidly than that of $1 \mathrm{~g} / \mathrm{l}$. Therefore, these doses were chosen to confirm the levels of NF- $\mathrm{kB} / \mathrm{p} 65$ (p65) in the cell nucleus following stimulation (Fig. 8(d) and (f)). Fig. 8(d) shows that p65 was translocated into the nucleus within $15-30 \mathrm{~min}$ and then decreased gradually. Nuclear p65 levels were up-regulated faster and (a)

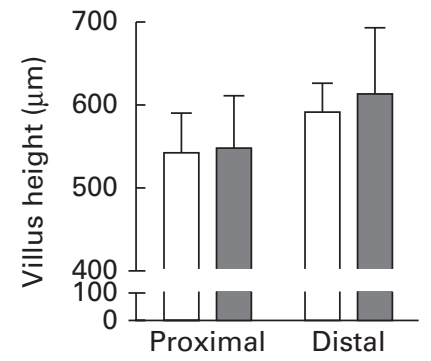

(b)

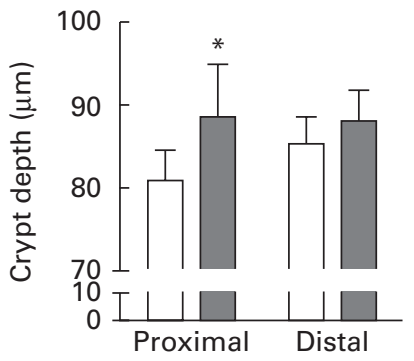

(c)

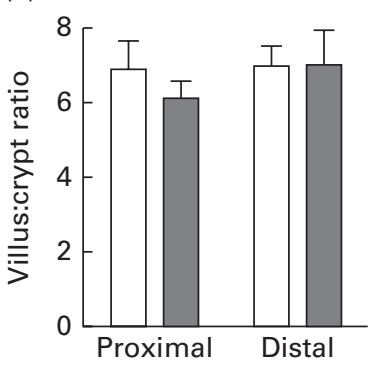

Fig. 2. (a) Villus height, (b) crypt depth and (c) villus:crypt ratio in the proximal and distal small intestine of pigs. Only healthy proximal and distal sections (necrotising enterocolitis (NEC) score 1 or 2) were considered. $\square$, Control pigs; $\square$, lactoferrin-enriched formula pigs. Values are means, with their standard errors represented by vertical bars. ${ }^{*}$ Mean value was significantly different from that of the control group $(P<0.05)$. 

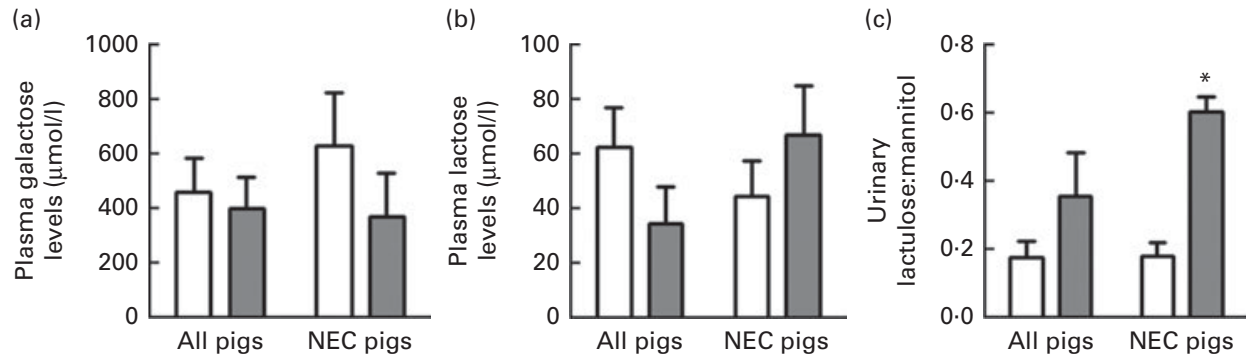

Fig. 3. Nutrient absorption and intestinal permeability in pigs: arterial plasma levels of galactose following (a) a given oral bolus of $5 \%$ galactose $(15 \mathrm{ml} / \mathrm{kg})$ for $20 \mathrm{~min}$ or (b) an oral bolus of $10 \%$ lactose $(15 \mathrm{ml} / \mathrm{kg})$. (c) Ratio of $5 \%$ lactulose:5\% mannitol $(15 \mathrm{ml} / \mathrm{kg})$ in urine samples after $3-5 \mathrm{~h}$ of an oral bolus of lactulose and mannitol before euthanasia. $\square$, Control pigs; $\square$, lactoferrin-enriched formula pigs. Values are means, with their standard errors represented by vertical bars. ${ }^{*}$ Mean value was significantly different from that of the control group $(P<0.05)$. NEC, necrotising enterocolitis.

more intensely with the bLF dose at $10 \mathrm{~g} / 1$ than that at $1 \mathrm{~g} / 1$ $(P<0 \cdot 05$; Fig. 8(d) and (f)).

Regarding the HIF- $1 \alpha$ signalling pathway, only the bLF dose at $10 \mathrm{~g} / \mathrm{l}$ led to the up-regulation of HIF-1 $\alpha$ levels, compared with the control (no treatment) and lower bLF doses (Fig. 8(g) and (h)).

\section{Discussion}

Various bioactive milk components, which are deficient in mature milk and infant formulas, may contribute to the protective effects of human and bovine colostrum against $\mathrm{NEC}^{(7,8,35)}$ Supplementation of bioactive proteins at doses similar to those in human or bovine colostrum might exert prophylaxis against inflammation, and may be important for the development of more effective infant formulas for preterm infants. We hypothesised that a high lactoferrin content in human colostrum is one of several important factors necessary to provide protection against NEC development in preterm infants. Moreover, based on the high degree of amino acid homology between human lactoferrin and bLF, a bLF-enriched formula may exert effects similar to those of human lactoferrin. We investigated this in our preterm pig model by administering $10 \mathrm{~g} / \mathrm{l}$ of bLF-enriched formula, close to the lactoferrin concentration in human colostrum and equivalent to $1.2 \mathrm{~g} / \mathrm{kg}$ per $\mathrm{d}$ in the period of TEN. This dose was greater than those used in previous studies which showed negligible effects against $\mathrm{NEC}^{(24,25)}$ and, consequently, was hypothesised to exert stronger protective effects against NEC. Enteral feeding of a $10 \mathrm{~g} / \mathrm{l}$ of bLF-enriched formula did not, however, decrease the sensitivity of the pigs to develop NEC. At this dose, bLF appeared to exacerbate disease severity in those pigs that developed NEC compared with CON pigs, as greater NEC severity and intestinal permeability were induced in the LF pigs. In addition, the LF pigs showed a tendency of a less mature gut with a lower small-intestinal weight than the CON pigs. In contrast, an important effect of bLF was the lower levels of IL-1 $\beta$ observed in the proximal small intestine of LF pigs. This may be explained by the ability of bLF to bind LPS derived from intestinal bacteria and thereby restrict LPS in inducing IL-1 $\beta$ release from enterocytes and immune cells ${ }^{(19)}$. bLF may act in a similar manner to limit IL- 8 release; however, bLF itself can also activate the $\mathrm{NF}-\kappa \mathrm{B}$ pathway and stimulate the release of IL-8 from enterocytes, as shown in the present in vitro data.
Therefore, two contrary effects of bLF on IL- 8 release may cause similar levels of IL- 8 in the intestinal tissues of CON and LF pigs. Lower doses of bLF administration could be beneficial to the immature intestine exerting bLF-LPS binding and also limiting excessive amounts of unbound bLF from stimulating unnecessary immune responses leading to a high release of IL-8.

To our knowledge, the present animal study is the first study to investigate the effects of bLF against NEC in preterm pigs at a dose close to that present in human colostrum. In germ-free newborn pigs, a high dose of bLF $(20 \mathrm{~g} / 1$ of bLF in formulafed pigs every $4 \mathrm{~h}$ ) evoked protective effects against lethal shock induced by endotoxin ${ }^{(36)}$. The opposing effects of bLF demonstrated in the present study may be explained by both
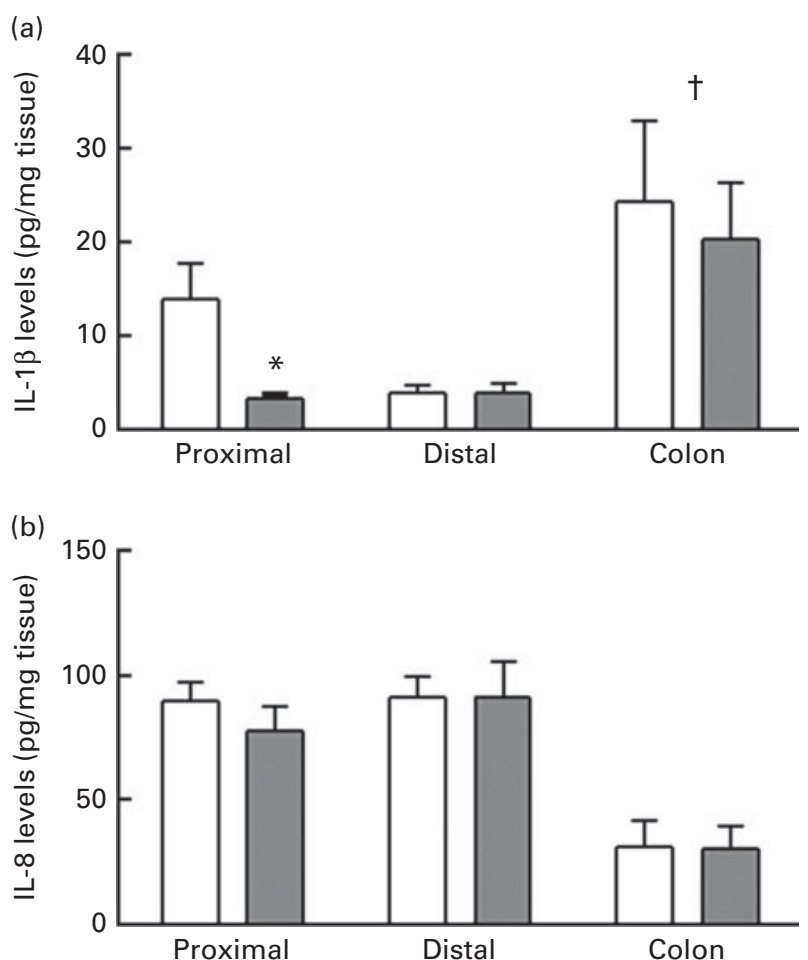

Fig. 4. IL-1 $\beta$ and IL-8 levels in the proximal and distal small-intestinal tissues and the colon tissues. $\square$, Control pigs; $\square$, lactoferrin-enriched formula pigs. Values are means, with their standard errors represented by vertical bars. * Mean value was significantly different from that of the control group $(P<0.05)$. †Pooled mean of the two pig groups was significantly different from that for the distal region $(P<0.05)$. 

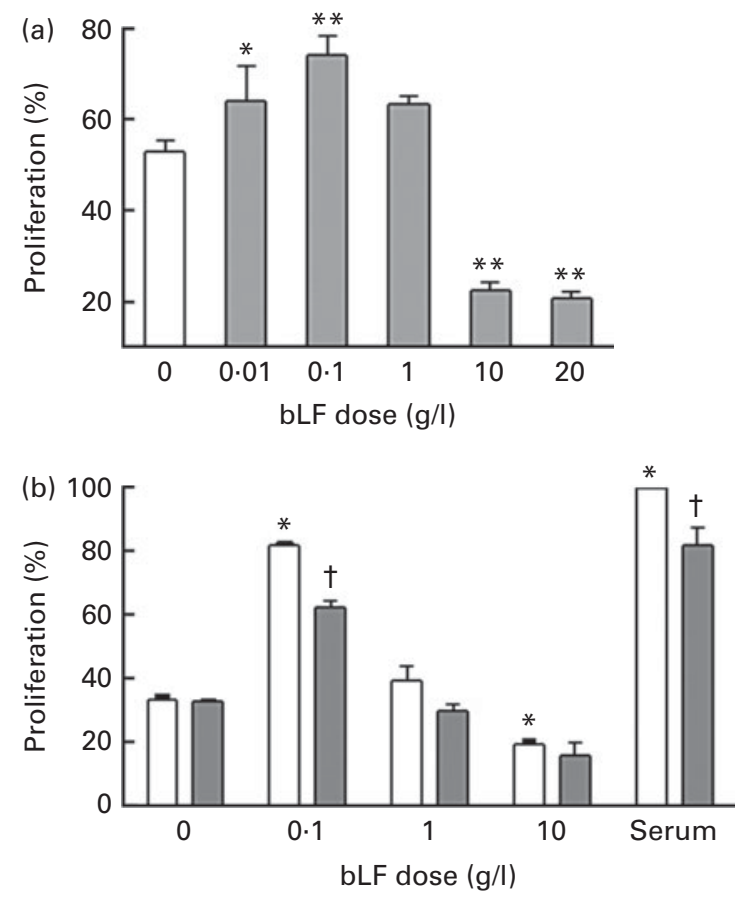

Fig. 5. Dose-dependent effects of bovine lactoferrin (bLF) in vitro on cell proliferation regulated by extracellular signal-regulated kinase (ERK). (a) Cells were stimulated with bLF $(0.01-20 \mathrm{~g} / \mathrm{l})$ in serum-free medium for $48 \mathrm{~h}$.

(b) Cells were treated with the ERK inhibitor PD98059 $(75 \mu \mathrm{M})$ or vehicle (dimethylsulphoxide) for $1 \mathrm{~h}$ before stimulation with bLF $(0-10 \mathrm{~g} / \mathrm{l})$ in either serum-free medium or serum medium for $48 \mathrm{~h}$. Values are absorbance at $490 \mathrm{~nm}$ normalised to percentage compared with those from cells treated with (a) serum medium or (b) serum medium plus vehicle. (b) $\square$, Vehicle; $\square$, PD98059. Values are means $(n 4)$, with their standard errors represented by vertical bars. (a) Mean value was significantly different from that of the control group (bLF $0 \mathrm{~g} / \mathrm{l})$ : ${ }^{*} P<0.05,{ }^{*} P<0.01$. (b) ${ }^{*}$ Mean value was significantly different from that of the control (bLF $0 \mathrm{~g} / \mathrm{l})(P<0.05)$. † Mean value was significantly different from that of the vehicle $(P<0.05)$.

gut prematurity and colonisation. The morphology of the immature gut and the immune system of preterm pigs may lead to different immune responses and inflammatory cascades under the presence of bLF at high doses (10-20 g/1), compared with that in term pigs. Therefore, the amounts of bioactive protein supplemented to infant formulas may be very crucial depending on whether it is administered to term or preterm infants. An oral administration of bLF decreased dextran sulphate sodium-induced colitis, inflammatory lesions, degree of colon shortening, as well as attenuated pro-inflammatory cytokines such as IL-6, IL-1 $\beta$ and TNF- $\alpha$ in 7-week-old rats when administered at lower doses of bLF (0.24-0.4 $\mathrm{g} \mathrm{bLF} / \mathrm{kg}$ per d) ${ }^{(25)}$ than that used in the present study. A direct comparison of the results is, however, difficult due to the differences in species and the degree of prematurity. Although the dextran sulphate sodium model of colitis correlates in several parameters with human inflammatory bowel disease, it does not reflect the intestinal inflammatory state that we observe in preterm pigs that developed NEC spontaneously in response to enteral feeding ${ }^{(16,37)}$. In another study, bLF $(0 \cdot 1 \mathrm{~g}$ bLF/d $)$ given to low-birth-weight infants prevented late-onset sepsis, but not $\mathrm{NEC}^{(24)}$. However, when a bLF dose of $100 \mathrm{mg} / \mathrm{d}$ was administered together with Lactobacillus rhamnosus GG, an attenuation of NEC incidence was observed ${ }^{(24)}$. This suggests that bLF may influence the gastrointestinal tract in synergistic ways with other bioactive components, such as probiotics.

The earlier studies showing the prophylaxis of bLF against dextran sulphate sodium-induced colitis and sepsis but not NEC $\left(0 \cdot 24-0 \cdot 4 \mathrm{~g} \mathrm{bLF} / \mathrm{kg}\right.$ per $\mathrm{d}^{(25)}$ and $\left.0 \cdot 1 \mathrm{~g} \mathrm{bLF} / \mathrm{d}^{(24)}\right)$ together with our observations of the detrimental effects of bLF at a higher dose $(1.2 \mathrm{~g} / \mathrm{kg}$ per $\mathrm{d})$ against NEC, but a positive effect on the IL-1 $\beta$ reduction led to the hypothesis that the protective effects of bLF against NEC and inflammation may be dose-dependent. For this purpose, different doses of bLF were tested in vitro. The present results illustrate that bLF interacts with intestinal epithelial cells in a dose-dependent manner between bLF concentrations of $0 \cdot 1,1$ and $10 \mathrm{~g} / \mathrm{l}$. These amounts of bLF are similar to those found in bovine term milk, bovine colostrum/human term milk and human colostrum, respectively ${ }^{(9-11)}$. Lactoferrin has been reported to be stable during gastrointestinal digestion in infants ${ }^{(10,38)}$, and therefore its major proportion from enteral feeding will be present in the gut lumen to interact with enterocytes. Levels of bLF administered during enteral feeding will, however, not be equivalent to the concentrations finally interacting with the epithelium due to dilution of the administered dose by gastric and pancreatic secretions. However, in some locations of the small intestine, a large amount of water and solutes are absorbed by passive or active transport ${ }^{(39)}$, which will result in higher concentrations of bLF. Therefore, the range of $0 \cdot 1-10 \mathrm{~g} / \mathrm{l}$ of bLF doses tested in vitro was reasonable for mechanistic investigation. In the present study, low doses
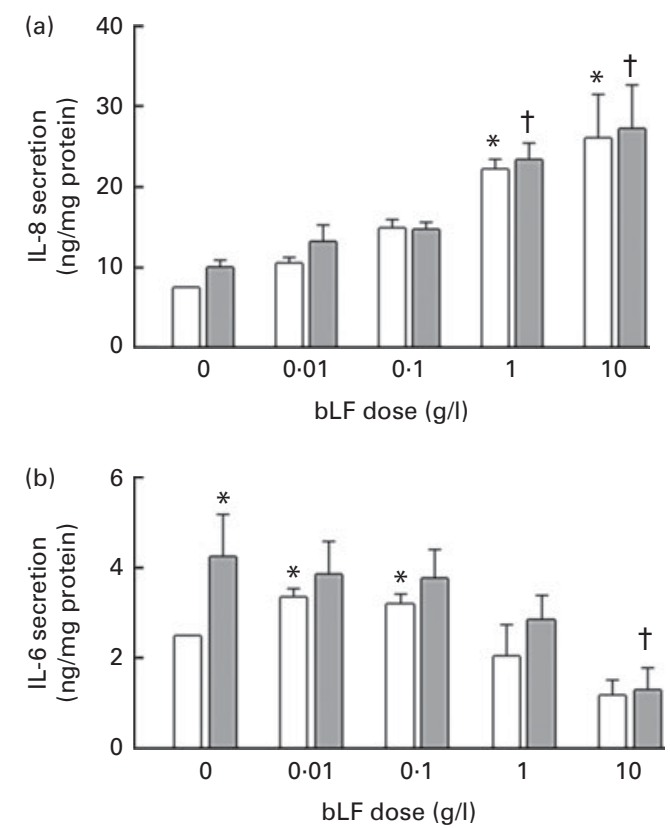

Fig. 6. Dose-dependent effects of bovine lactoferrin (bLF) $(0-10 \mathrm{~g} / \mathrm{l})$ on lipopolysaccharide (LPS) $(0.1 \mu \mathrm{g} / \mathrm{ml})$-induced pro-inflammatory cytokine secretion: (a) IL-8 and (b) IL-6. Cells were stimulated with LPS and/or bLF for $24 \mathrm{~h}$. $\square$, Without LPS addition; $\square$, with LPS addition $(0.1 \mu \mathrm{g} / \mathrm{ml})$. Values are means $(n 3)$, with their standard errors represented by vertical bars. * Mean value was significantly different from that of the control (no treatment) $(P<0.05)$. † Mean value was significantly different from that of the LPS-alone treatment $(P<0.05)$. 
(a)

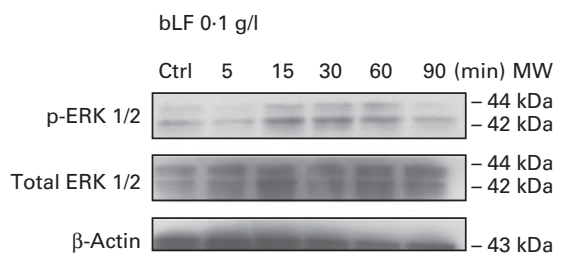

(c)

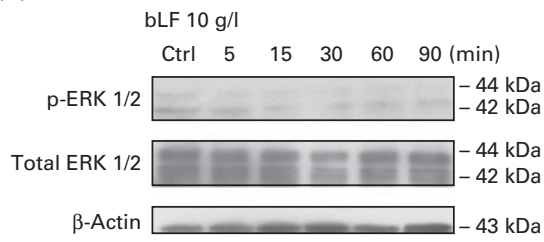

(b)

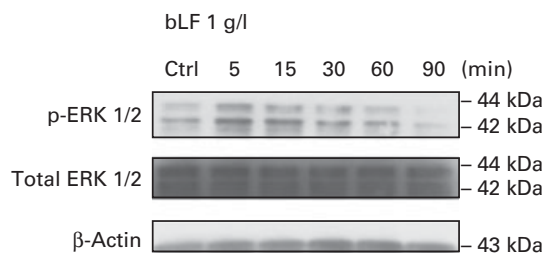

(d)

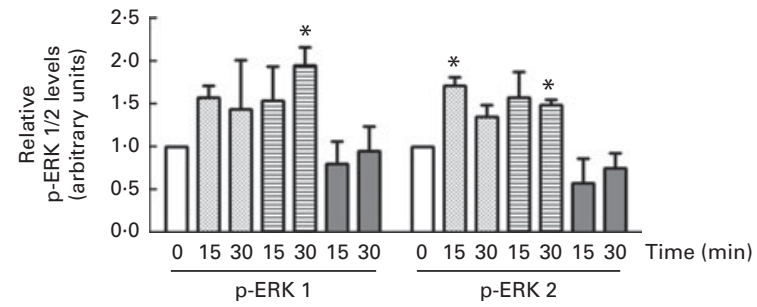

(e)

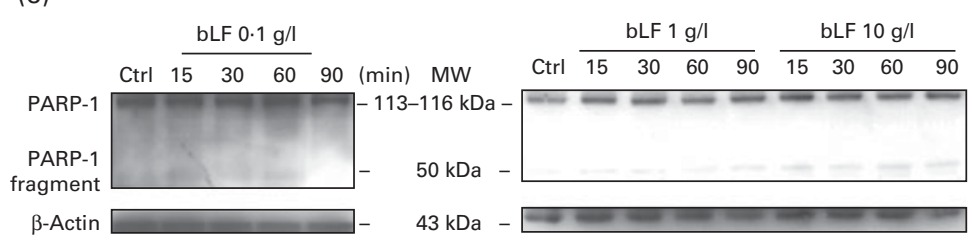

(f)

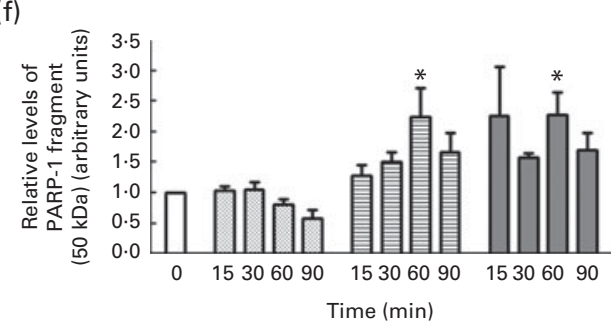

Fig. 7. Dose-dependent effects of bovine lactoferrin (bLF) on the phosphorylation of extracellular signal-regulated kinase (ERK) $1 / 2$ and the cleavage of poly(ADP-ribose) polymerase 1 (PARP-1). Cells were stimulated with bLF at a dose of $0 \cdot 1,1$ or $10 \mathrm{~g} / \mathrm{l}$ for the time periods indicated. Cell lysates were blotted using the phosphorylated ERK (p-ERK) 1/2 antibody ((a)-(c)) or the PARP-1 antibody (e). Quantitative analysis by the densitometry of representative p-ERK $1 / 2$ bands (d) and $50 \mathrm{kDa}$ PARP-1 fragment (f) normalised relative to the control (no treatment). $\square$, Control (Ctrl); $\mathrm{g}, \mathrm{bLF} 0.1 \mathrm{~g} / \mathrm{l} ; \mathrm{l}, \mathrm{bLF} 1 \mathrm{~g} / \mathrm{l} ; \square$, bLF $10 \mathrm{~g} / \mathrm{l}$. Values are means $(n 3)$, with their standard errors represented by vertical bars. * Mean value was significantly different from that of the control $(P<0 \cdot 05)$. MW, molecular weight.

of bLF $(0 \cdot 1-1 \mathrm{~g} / \mathrm{l})$ stimulated cell proliferation through the activation of the ERK pathway, prevented IL- 8 secretion and inhibited the activation of both NF- $\mathrm{BB}$ and HIF- $1 \alpha$. In contrast, at higher concentrations $(1-10 \mathrm{~g} / 1)$, bLF exerted a suppression of cell growth and inhibited ERK activation, leading to IL-8 secretion and NF-кB and HIF- $1 \alpha$ activation.

Similar results from low doses of bLF $(0 \cdot 4 \mathrm{~g} / \mathrm{l})$ on intestinal cell proliferation have been observed previously, which were also mediated through ERK activation ${ }^{(18)}$. A dose-dependent effect has also been reported for concentrations of bLF at the lower range of $0 \cdot 1-1000 \mu \mathrm{g} / \mathrm{ml}^{(17)}$. Additionally, a greater stimulatory effect has been observed for apo-bLF on proliferation ${ }^{(18)}$. Moreover, the increase in cell proliferation following stimulation with bLF at doses of $0 \cdot 1-1 \mathrm{~g} / \mathrm{l}$ and the suppressive effect of the inhibitor PD98059 on cell proliferation at the bLF dose of $0 \cdot 1 \mathrm{~g} / 1$ suggest that ERK $1 / 2$ activation is involved in cell proliferation induced at low doses of bLF. This effect implies that at appropriate levels, bLF is likely to stimulate the maturation of the small intestine in newborn infants through ERK $1 / 2$. The activation of ERK 1/2, a member of mitogen-activated protein kinase pathway family, has been extensively correlated with cell proliferation in various studies ${ }^{(18,40,41)}$, and these results also support this involvement. In contrast, at a higher dose $(10 \mathrm{~g} / 1)$, bLF did not activate ERK $1 / 2$, and a lower rate of cell proliferation than in control cells was observed, indicating that cell death may occur. The generation of the $50 \mathrm{kDa}$ fragment from PARP-1 observed in the present study suggests that bLF concentrations between 1 and $10 \mathrm{~g} / 1$ stimulate cell necrosis, but not apoptosis, and these results agree with the observation of poor cell proliferation at the bLF dose of $10 \mathrm{~g} / \mathrm{l}$.

Data from both the in vivo pig study and also from the in vitro cell proliferation studies raised questions whether high bLF doses led to a negative impact and excessive inflammation in preterm neonates. Several studies have indicated that inflammation and NEC are related to high levels of inflammatory cytokines such as IL- 8 and IL-6 in the gut ${ }^{(42-44)}$. Therefore, we tested the release of IL- 8 and IL- 6 following stimulation with both LPS and bLF in vitro. LPS stimulation of PsIc1 cells induced IL- 6 but not IL- 8 secretion. bLF treatments caused changes in the levels of IL- 6 , but at the dose of $10 \mathrm{~g} / 1$, it attenuated LPS-induced IL- 6 release. bLF may in this way bind to LPS and thereby limit the inductive effect of LPS on IL- $6^{(19)}$. This may also explain the greater levels of IL-1 $\beta$ observed in the proximal small intestine of the group CON group compared with the LF group in the pig study. The lack of changes in the levels of IL- 8 between the LPS and LPS + bLF treatments illustrates that bLF itself may be the main factor for IL- 8 release in the range of $1-10 \mathrm{~g} b L F / 1$. On the other hand, some bioactive proteins decreased LPS-induced IL-8 release in the more LPS-sensitive cell line 
(a) bLF $0.1 \mathrm{~g} / \mathrm{l}$

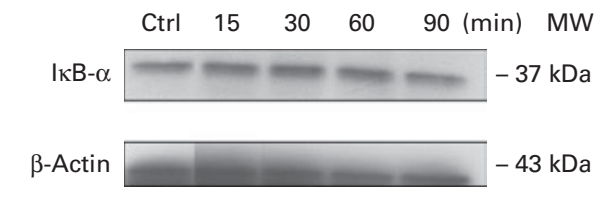

(c) bLF $10 \mathrm{~g} / \mathrm{l}$
$\mathrm{Ctrl} \quad 15 \quad 30 \quad 60 \quad 90(\mathrm{~min}) \quad \mathrm{MW}$

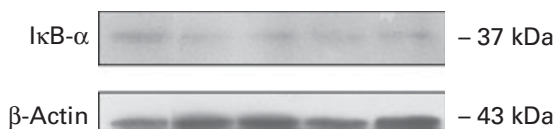

(e)

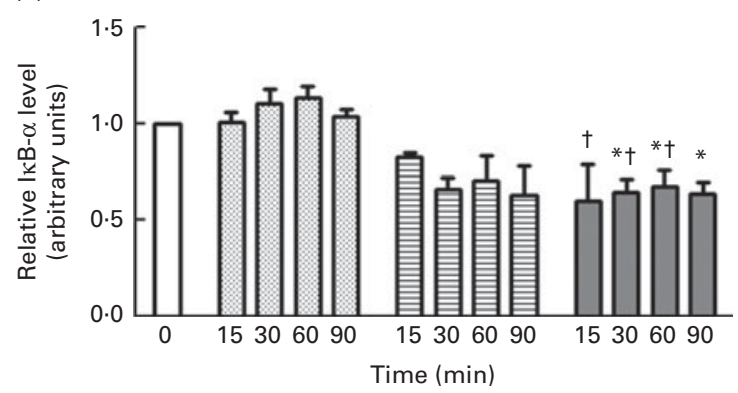

(g)

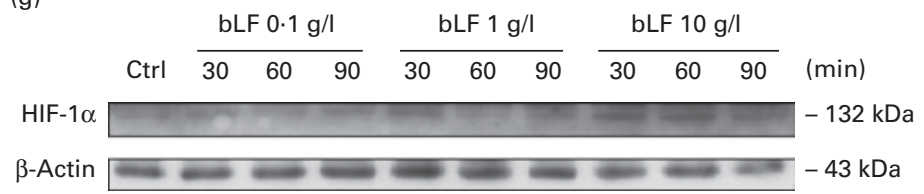

(b)

$$
\text { bLF } 1 \mathrm{~g} / \mathrm{l}
$$

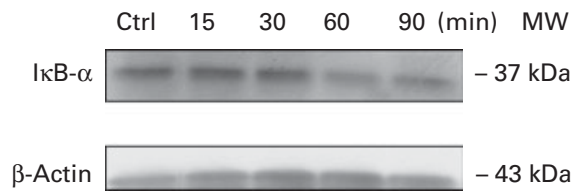

(d)

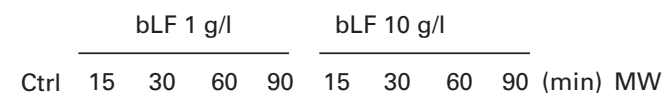

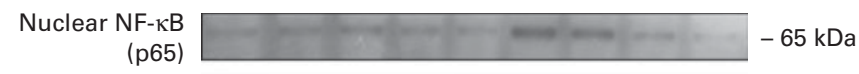

Nuclear lamin B1 $-67 \mathrm{kDa}$

Fig. 8. Dose-dependent effects of bovine lactoferrin (bLF) on the activation of NF-kB and hypoxia-inducible factor-1 $\alpha$ (HIF-1 $\alpha$ ). Cells were stimulated with bLF at a dose of (a) $\mathbf{0 . 1}$, (b) 1 or (c) $10 \mathrm{~g} / \mathrm{l}$ for the time periods indicated, and cell lysates were blotted using the inhibitor $\mathrm{\kappa B}-\alpha$ (IkB- $\alpha$ ) antibody or (g) the HIF-1 $\alpha$ antibody. (d) Cells were treated with bLF at a dose of 1 or $10 \mathrm{~g} / \mathrm{l}$ for $15-90 \mathrm{~min}$, and then nuclear extracts were blotted with the NF-kB/p65 antibody. Quantitative analysis

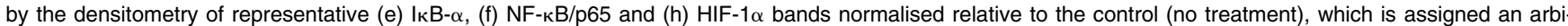
trary unit of 1. $\square$, Control; $⿴ 囗 \mathrm{~g}, \mathrm{bLF} 0.1 \mathrm{~g} / \mathrm{l}$; 目, bLF $1 \mathrm{~g} / \mathrm{l} ; \square, \mathrm{bLF} 10 \mathrm{~g} / \mathrm{l}$. Values are means $(n 3)$, with their standard errors represented by vertical bars. ${ }^{*}$ Mean value was significantly different from that of the control group $(P<0.05)$. (e, h) † Mean value was significantly different from that of bLF $0.1 \mathrm{~g} / \mathrm{l}$ for the respective time period $(P<0.05)$. (f) † Mean value was significantly different from that of bLF $1 \mathrm{~g} / \mathrm{l}$ for the respective time period $(P<0.05)$.

$(\mathrm{H} 4)^{(45,46)}$, which indicate that in those cells, particularly low doses of bLF may also attenuate LPS-induced IL-8 secretion evoked by bLF-LPS binding. Cytokine data in the present in vivo and in vitro studies suggest that bLF can bind to LPS of the intestinal bacteria and prevent excessive immune responses, and that high bLF doses itself can initiate IL-8 release.

We observed an effect of bLF on NF-кB activation only by stimulation at the dose of $10 \mathrm{~g} / \mathrm{l}$ but not at lower doses (Fig. 8). As an indicator of inflammation, NF-кB leads to the release of IL- $8^{(33,34)}$. Our data showed that bLF at a concentration of $10 \mathrm{~g} / 1$ stimulates the release of IL- 8 and activates the NF- $\mathrm{BB}$ pathway by $\mathrm{p} 65$ nuclear translocation. This may be related to the negative effect of bLF concentration at $10 \mathrm{~g} / \mathrm{l}$ observed in the pig study, indicating the activation of
$\mathrm{NF}-\kappa \mathrm{B}$ in the intestine of the LF pigs in an excessive manner, thereby causing more severe inflammation rather than protecting them against NEC. Our findings regarding the activation of $\mathrm{NF}-\kappa \mathrm{B}$ following stimulation with bLF are in accordance with several studies performed in neutrophils $^{(42,47,48)}$. In contrast, some studies have shown that bLF may exert anti-inflammatory effects by attenuating LPS-induced IL-8 or TNF- $\alpha^{(20,49)}$, or inhibit NF- $\mathrm{B}$, TNF receptor-associated factor 6 (TRAF-6) and p38 pathways induced by LPS ${ }^{(50)}$. These studies were conducted at bLF concentrations below $1 \mathrm{~g} / 1$, which may be the reasons for no observed negative effects such as NF- $\mathrm{KB}$ activation by bLF itself.

The up-regulation of HIF- $1 \alpha$ is normally observed under hypoxic conditions and during Fe deficiency, which limit the 
automatic degradation of HIF- $1 \alpha$. Up-regulated HIF- $1 \alpha$ stimulates the transcription of a multitude of genes involved in cell survival under stress conditions ${ }^{(51)}$. The apo-form of bLF has been found to bind intracellular free $\mathrm{Fe}$ in rats, thereby subsequently stabilising HIF-1 $\alpha^{(22,23,51)}$. Stabilisation or upregulation of HIF- $1 \alpha$ was indicated as a possible therapy for intestinal bowel disease due to the promotion of barrier functions ${ }^{(51)}$. However, this protein has been correlated with hypoxic inflammation, and it is up-regulated as a consequence of NF- $\mathrm{NB}$ and cyclo-oxygenase- 2 activation induced by IL- $1 \beta^{(22)}$. HIF- $1 \alpha$ is also activated by cell stimulation with TNF- $\alpha$ or NO, and it participates in several inflammatory responses ${ }^{(22)}$. Therefore, an up-regulation of HIF-1 $\alpha$ and NF- $\kappa \mathrm{B}$ after the bLF treatment at a dose of $10 \mathrm{~g} / \mathrm{l}$, as shown in the present study, can be detrimental to the cells, for instance causing cell necrosis, inhibiting cell proliferation and releasing high levels of IL-8. To our knowledge, this is the first time bLF has been shown to exert a dose-dependent effect on HIF-1 $\alpha$ up-regulation in intestinal cells. In the future, the crosstalk and synergistic effects of HIF- $1 \alpha$ and NF-кB could be interesting to pursue to clarify the roles of these pathways mediated by bLF.

Overall, this preterm pig study indicates that a bLF dose of $10 \mathrm{~g} / \mathrm{l}$ lowers IL-1 $\beta$ levels in the proximal small intestine, but does not protect preterm pigs against NEC. bLF at this dose tends to exacerbate NEC severity and decrease intestinal functions by lowering small-intestinal weight and increasing intestinal permeability in pigs that develop NEC. In combination with the in vitro experiments exploring a range of bLF doses, the present study suggests that only lower doses of lactoferrin may potentially be beneficial for preterm neonates to dampen the inflammatory mediators. Consequently, the supplementation of infant formulas with appropriate levels of bLF should be more carefully studied before its usage for preterm infants. Further pig studies are necessary to investigate the effects of various bLF doses before concluding any protective effects of this protein in vivo.

\section{Supplementary material}

To view supplementary material for this article, please visit http://dx.doi.org/10.1017/S0007114513002456

\section{Acknowledgements}

We would like to thank Mette Schmidt, Bente Winther Synnestvedt and Mandy Joanne Greig for help with animal procedures and Elin Skytte for laboratory assistance. We also thank Mette Viberg Østergaard for setting up cell culture protocols for PsIc1 cells.

The present study was supported by the Danish Dairy Research Foundation. The Danish Dairy Research Foundation had no role in the design, analysis or writing of this article.

Y. L. is employed by Arla Foods Ingredients. Although Y. L. participated in the design of the study and interpretation of the results, the responsibility for the final manuscript was taken with the remaining authors who have no potential conflicts of interest.
D. E. W. C., P. T. S., S. B. B. and D. N. N. contributed to the concept and design of the study. D. N. N. was responsible for the in vitro studies. D. N. N. and Y. L. conducted the animal study and performed the data analysis. All authors contributed to the data interpretation and manuscript writing. D. N. N. had primary responsibility for the final content. All authors accepted the final manuscript.

\section{References}

1. Neu J \& Walker WA (2011) Necrotizing enterocolitis. N Engl J Med 364, 255-264.

2. Kelley L (2012) Increasing the consumption of breast milk in low-birth-weight infants: can it have an impact on necrotizing enterocolitis? Adv Neonatal Care 12, 267-272.

3. Merewood A, Brooks D, Bauchner H, et al. (2006) Maternal birthplace and breastfeeding initiation among term and preterm infants: a statewide assessment for Massachusetts. Pediatrics 118, e1048-e1054.

4. Lucas A \& Cole TJ (1990) Breast milk and neonatal necrotising enterocolitis. Lancet 336, 1519-1523.

5. Donovan SM (2006) Role of human milk components in gastrointestinal development: current knowledge and future NEEDS. J Pediatr 149, S49-S61.

6. Boyd CA, Quigley MA \& Brocklehurst P (2007) Donor breast milk versus infant formula for preterm infants: systematic review and meta-analysis. Arch Dis Child Fetal Neonatal Ed 92, F169-F175.

7. McGuire W \& Anthony M (2003) Donor human milk versus formula for preventing necrotising enterocolitis in preterm infants: systematic review. Arch Dis Child Fetal Neonatal Ed 88, F11-F14.

8. Sullivan S, Schanler RJ, Kim JH, et al. (2010) An exclusively human milk-based diet is associated with a lower rate of necrotizing enterocolitis than a diet of human milk and bovine milk-based products. J Pediatr 156, 562-567e1.

9. Marshall K (2004) Therapeutic applications of whey protein. Altern Med Rev 9, 136-156.

10. Chatterton DEW, Rasmussen JT, Heegaard CW, et al. (2004) In vitro digestion of novel milk protein ingredients for use in infant formulas: research on biological functions. Trends Food Sci Technol 15, 373-383.

11. Baker EN \& Baker HM (2009) A structural framework for understanding the multifunctional character of lactoferrin. Biochimie 91, 3-10

12. González-Chávez SA, Arévalo-Gallegos S \& Rascón-Cruz Q (2009) Lactoferrin: structure, function and applications. Int J Antimicrob Agents 33, 301.e1-301.e8.

13. Kawakami H \& Lönnerdal B (1991) Isolation and function of a receptor for human lactoferrin in human fetal intestinal brush-border membranes. Am J Physiol 261, G841-G846.

14. Lönnerdal B, Jiang R \& Du X (2011) Bovine lactoferrin can be taken up by the human intestinal lactoferrin receptor and exert bioactivities. J Pediatr Gastroenterol Nutr 53 , 606-614.

15. Lopez V, Suzuki YA \& Lönnerdal B (2006) Ontogenic changes in lactoferrin receptor and DMT1 in mouse small intestine: implications for iron absorption during early life. Biochem Cell Biol 84, 337-344.

16. Adamkin DH (2012) Mother's milk, feeding strategies, and lactoferrin to prevent necrotizing enterocolitis. JPEN J Parenter Enteral Nutr 36, 25S-29S.

17. Buccigrossi V, De Marco G, Bruzzese E, et al. (2007) Lactoferrin induces concentration-dependent functional 
modulation of intestinal proliferation and differentiation. Pediatr Res 61, 410-414.

18. Jiang R, Lopez V, Kelleher SL, et al. (2011) Apo- and holo-lactoferrin are both internalized by lactoferrin receptor via clathrin-mediated endocytosis but differentially affect ERK-signaling and cell proliferation in Caco-2 cells. $J$ Cell Physiol 226, 3022-3031.

19. Håversen L, Ohlsson BG, Hahn-Zoric M, et al. (2002) Lactoferrin down-regulates the LPS-induced cytokine production in monocytic cells via NF-kappa B. Cell Immunol 220, $83-95$.

20. Berlutti F, Schippa S, Morea C, et al. (2006) Lactoferrin downregulates pro-inflammatory cytokines upexpressed in intestinal epithelial cells infected with invasive or noninvasive Escherichia coli strains. Biochem Cell Biol 84, 351-357.

21. Baker HM \& Baker EN (2004) Lactoferrin and iron: structural and dynamic aspects of binding and release. Biometals $\mathbf{1 7}$, 209-216.

22. Jung Y-J, Isaacs JS, Lee S, et al. (2003) IL-1beta-mediated upregulation of HIF-1alpha via an NFkappaB/COX-2 pathway identifies HIF-1 as a critical link between inflammation and oncogenesis. FASEB J 17, 2115-2117.

23. Zakharova ET, Kostevich VA, Sokolov AV, et al. (2012) Human apo-lactoferrin as a physiological mimetic of hypoxia stabilizes hypoxia-inducible factor-1 alpha. Biometals $\mathbf{2 5}$, 1247-1259.

24. Manzoni P, Rinaldi M, Cattani S, et al. (2009) Bovine lactoferrin supplementation for prevention of late-onset sepsis in very low-birth-weight neonates: a randomized trial. JAMA 302, 1421-1428.

25. Togawa J-I, Nagase H, Tanaka K, et al. (2002) Oral administration of lactoferrin reduces colitis in rats via modulation of the immune system and correction of cytokine imbalance. J Gastroenterol Hepatol 17, 1291-1298.

26. Sangild PT, Siggers RH, Schmidt M, et al. (2006) Diet- and colonization-dependent intestinal dysfunction predisposes to necrotizing enterocolitis in preterm pigs. Gastroenterology 130, 1776-1792.

27. Cilieborg MS, Boye M, Thymann T, et al. (2011) Diet-dependent effects of minimal enteral nutrition on intestinal function and necrotizing enterocolitis in preterm pigs. JPEN J Parenter Enteral Nutr 35, 32-42.

28. Thymann T, Burrin DG, Tappenden KA, et al. (2006) Formula-feeding reduces lactose digestive capacity in neonatal pigs. Br J Nutr 95, 1075-1081.

29. Bjornvad CR, Thymann T, Deutz NE, et al. (2008) Enteral feeding induces diet-dependent mucosal dysfunction, bacterial proliferation, and necrotizing enterocolitis in preterm pigs on parenteral nutrition. Am J Physiol Gastrointest Liver Physiol 295, G1092-G1103.

30. Bjornvad CR, Schmidt M, Petersen YM, et al. (2005) Preterm birth makes the immature intestine sensitive to feedinginduced intestinal atrophy. Am J Physiol Regul Integr Comp Physiol 289, R1212-R1222.

31. Whitacre CM, Zborowska E, Willson JKV, et al. (1999) Detection of poly(ADP-ribose) polymerase cleavage in response to treatment with topoisomerase I inhibitors: a potential surrogate end point to assess treatment effectiveness. Clin Cancer Res 5, 665-672.

32. Gobeil S, Boucher CC, Nadeau D, et al. (2001) Characterization of the necrotic cleavage of poly(ADP-ribose) polymerase (PARP-1): implication of lysosomal proteases. Cell Death Differ 8, 588-594.

33. Rautava S, Lu L, Nanthakumar NN, et al. (2011) TGF- $\beta 2$ induces maturation of immature human intestinal epithelial cells and inhibits inflammatory cytokine responses induced via the NF-кB pathway. J Pediatr Gastroenterol Nutr $\mathbf{5 4}$, 630-638.

34. Karin M \& Greten FR (2005) NF-kappaB: linking inflammation and immunity to cancer development and progression. Nat Rev Immunol 5, 749-759.

35. Møller HK, Thymann T, Fink LN, et al. (2011) Bovine colostrum is superior to enriched formulas in stimulating intestinal function and necrotising enterocolitis resistance in preterm pigs. Br J Nutr 105, 44-53.

36. Lee WJ, Farmer JL, Hilty M, et al. (1998) The protective effects of lactoferrin feeding against endotoxin lethal shock in germfree piglets. Infect Immun 66, 1421-1426.

37. Fischer R, Debbabi H, Blais A, et al. (2007) Uptake of ingested bovine lactoferrin and its accumulation in adult mouse tissues. Int Immunopharmacol 7, 1387-1393.

38. Eriksen EK, Holm H, Jensen E, et al. (2010) Different digestion of caprine whey proteins by human and porcine gastrointestinal enzymes. Br J Nutr 104, 374-381.

39. Hinsberger A \& Sandhu BK (2004) Digestion and absorption. Curr Paediatr 14, 605-611.

40. Pearson G, Robinson F, Beers Gibson T, et al. (2001) Mitogen-activated protein (MAP) kinase pathways: regulation and physiological functions. Endocr Rev 22, 153-183.

41. Boutros T, Chevet E \& Metrakos P (2008) Mitogen-activated protein (MAP) kinase/MAP kinase phosphatase regulation: roles in cell growth, death, and cancer. Pharmacol Rev 60, $261-310$.

42. Ando K, Hasegawa K, Shindo K-I, et al. (2010) Human lactoferrin activates NF-kappaB through the Toll-like receptor 4 pathway while it interferes with the lipopolysaccharidestimulated TLR4 signaling. FEBS J 277, 2051-2066.

43. Sorimachi K, Akimoto K, Hattori Y, et al. (1997) Activation of macrophages by lactoferrin: secretion of TNF-alpha, IL-8 and NO. Biochem Mol Biol Int 43, 79-87.

44. Markel TA, Crisostomo PR, Wairiuko GM, et al. (2006) Cytokines in necrotizing enterocolitis. Shock 25, 329-337.

45. Rautava S, Nanthakumar NN, Dubert-Ferrandon A, et al. (2011) Breast milk-transforming growth factor- $\beta_{2}$ specifically attenuates IL-1 $\beta$-induced inflammatory responses in the immature human intestine via an SMAD6- and ERK-dependent mechanism. Neonatology 99, 192-201.

46. Claud EC, Savidge T \& Walker WA (2003) Modulation of human intestinal epithelial cell IL-8 secretion by human milk factors. Pediatr Res 53, 419-425.

47. Oh S-M, Pyo C-W, Kim Y, et al. (2004) Neutrophil lactoferrin upregulates the human p53 gene through induction of NF-kappaB activation cascade. Oncogene 23, 8282-8291.

48. Oh S-M, Lee S-H, Lee B-J, et al. (2007) A distinct role of neutrophil lactoferrin in RelA/p65 phosphorylation on Ser536 by recruiting TNF receptor-associated factors to IkappaB kinase signaling complex. J Immunol 179, 5686-5692.

49. Kruzel ML, Harari Y, Mailman D, et al. (2002) Differential effects of prophylactic, concurrent and therapeutic lactoferrin treatment on LPS-induced inflammatory responses in mice. Clin Exp Immunol 130, 25-31.

50. Inubushi T, Kawazoe A, Miyauchi M, et al. (2012) Molecular mechanisms of the inhibitory effects of bovine lactoferrin on lipopolysaccharide-mediated osteoclastogenesis. J Biol Chem 287, 23527-23536.

51. Colgan SP \& Taylor CT (2010) Hypoxia: an alarm signal during intestinal inflammation. Nat Rev Gastroenterol Hepatol 7, 281-287. 